\title{
APPLICATION OF AHP TO \\ THE DETERMINATION OF THE QUALITY CLASS OF CITY ECOLOGICAL ENVIRONMENT
}

\author{
XU GUOMING
}

Tianjin Institute of Environmental Protection Sciences

Tianjin, China.

\begin{abstract}
A wighting system of the city ecological environmental quality criteria has been established by using The Analytical Hierarchy Process (AHP). This system successfully describe the related ecological environmental quality class standards and the quantitative relationship between the environmental factors of the comprehensive environmental quality models. The results is also satisfactory when applied this system to the analyses of the city ecological environmental quality class.
\end{abstract}

\section{Foreword}

Nowadays, the main work for the method of determining city ecological environmental quality class is to establish, on the basis of the decided environmental criteria system, the corresponding quality standard which is composed of quality evaluation criteria, classified standard and classified standard of city comprehensive quality. While making an analysis of a certain city environmental quality, one thinks that city environmental criteria quality should be synthesized to obtain a resultant value of city environmental quality, and to present a contrast with the classified standard of city environmental quality, as a result. the city environmental quality class can be thus determined.

In order to establish the classified standard system of determining city ecological environmental quality and synthesizing city environmental quality, it is necessary that the findings must be reasonable and scientific, and in the meantime the effect on environment caused by environmental factors (criteria) must be analyzed and the weights to entronmental quality contributed by those factors must be also determined. Now that the city (area) environmental quality results from the coordinative effects of all environmental factors and there exists a great difference among the factors' role, the way of action and the degree of effect on city environment, therefore. their contributions to environmental quality are different respectively.

Recently, while studying city entironmental quality. many foreign and Chinese experts have adopted "Principal component-factor analysis" (1), 2$\}, 13\}$. one of the methods to determine environmental factors weights, such a method is mainit applied to the scientific analysis of the natural environment - We have also been adopting the method to verify the reasonableness of AHP findings with a satisfactory result as we made an analysis of the corresponding city natural environmental quality.

In the research of determining city ecological environmental quality we have adopted AHP. firstly proposed by T.L. Saaty. to make a quantitative analysis of the weights relation among the city environmental factors. But the findings obtained at home and abroad show 4,5 that AHP can 
only be used to arrange in quantitative order of envisonmenta, factotrs importance, while city environmental quality, especially concerning social environment is analysed. AHP is only limited to making a quaijtative contrast.

The purpose of this articie is to establish a scientific method for quantitative analysis of city ecological environmental quality by means of the quantitative relation (oltained through ÄHP) among environmental factors on the basis of studying the quality standards of city environmental criteria system.

In brief, we will introduce our work in the order of AHP. as follows:

1. The establishment of the structural model of city ecological environmenta] system.

The model is composed of three levels. The objective levels city ecological environment. The median level: consisting of nine environmental elements of city. The basic level, made up of twenty-five environmental criteria, each of them is subject to certain elements of the median level, but has no relationship to other elements. For the detail, refer to the following figure.

\begin{tabular}{|l|}
\hline Sulphur dioxide \\
\hline Nitrogen oxide \\
\hline Total suspended solid \\
\hline Solvent oxygen \\
\hline Oxygen for biochemistry \\
\hline Ammonia nitrogen \\
\hline Nitrite nitrogen \\
\hline Volatile phenol \\
\hline Traffic noise \\
\hline Density of population \\
\hline Housing area \\
\hline Number of commercial services \\
\hline Rate of gasification \\
\hline Consumption of service water \\
\hline Consumption of service electricity \\
\hline Number of vehicles \\
\hline Area of traffic roads \\
\hline Number of hospitals \\
\hline Number of hospital beds \\
\hline Number of doctors \\
\hline Number of theatres \\
\hline City green area \\
\hline Number of students in middle schools \\
\hline Number of students in the univetsities \\
\hline Number of scientists and technicians \\
\hline
\end{tabular}

2. The establishment of the information net of judgement matrices for city ecological environmental quality.

Environmental information directly results from the characteristics and effects of the environmental 
factors, or indirectly reflects from the facotrs effects on the other correlative factors, peoples and creatures in the ecological environment. All of these complicated relation of information and effect makes correlative relation of the ecological environmental factors.

So, it is necessary to establish two information networks for environmental quality, namely, one is the investigation network for inhabitants views on city environmental criteria quality, and the other, consultation network for experts views on city environmental elements quality.

\section{(1). Investigation of inhabitants view on city environmental criteria quality}

Inhabitants are the builder of city environment and their requirements can also be fulfiled by city environment. Many of their activities are carried out chiefly depending on all elements of city environment. No wonder inhabitants always take much care of surrounding environment and expect to take the maximum enjoyment from the environmental resources. In this way, the condition of city environmental quality is closely bound up with inhabitants' own interest. The quality of certain part of environment can be authentically reflected from inhabitants' response to each part of the exposed environment and their consequent judgement.

In order to collect the inhabitants' views on each criteria quality of city environment. it is necessary to work out a "Sampling investigation table of city social environmental quality". which is chiefly composed of twenty-five criteria of city environment. During the investigation, the inhabitants are required to draw qualitative conclusions for each criteria, that is, excellent (100), good ( 80$)$, pass $(60)$, poor (40), very poor(below 20 ). Inhabitants from 880 families, including those from every status, are investigated and they are subordinated to the neighbourhood committees of six districts of city.

\section{(2). Consultation of experts' views on the quality of city ecological environmental elements}

In the respect of structure and direct effect, each element of city environment is more complicated than that of environmental criterion. The composition of its. environmental quality is much more complex. This complexity of city environmental element is caused by two reasons, one is that there exists an interrelation and inter-effect among many environmental criteria compositions. the other is that these environmental elements are composed of something concerning natural science and sociology. which cover the scientific theories and policies concerning politics, economy and environment in the city construction planning. When the judgement matrix is established, the informant is required to have not only the specialised knowledge in the subject concerned, but also the experience in sociology, environmental science and the capability of making a logic judgement. To meet this requirement, we have invited the experts concerned to take part in making an analysis and judgement of city ecological environmental elements quality. The judgement matrix for city environmental element quality and the environmental quality weights are established on the basis of those experts' conciusions.

3. Formation of judgement matrix for city ecological environmental quality

Just on the basis of the information investigation on qualities of city environment criterion and element. the two judgement matrices for these lactors of these two levels are thus estabished.

(1). Formation of judgement matrix for envirommental criterion level 
Besides the investigation on the quality of social environmental criterion mentioned above, the information of the judgement matrix of the environmental criteria level to the natural environmenta part is mainly bused on the documents issued periodically by environmental protection departments. Now that the 25 criteria are subject to 9 environmental elements, so, their weights can be determined respectively depending on the 9 judgement matrices. indicated as following matrix:

$$
\text { (a)ij). } n \times n
$$

where: $\mathbf{n}$ is the criterion number, of which the environmental elements are comprised.

(2). Formation of judgement matrix for city environmental elements

$$
\left(a(i j) ; n \times n^{*} \quad n=9\right.
$$

The weights of the environmental elements quality are determined on the basis of this matrix and analysis, and the results are indicated in table 1.

4. The application of city environmental quality weights to the determination of the quality class of city ecolugicaj environment.

After the quality weights of city environmental criteria and elements, are determined, the quality index of both the environmental criteria and the elements can be weighted to obtain a synthesis value of the ecological environmental quality while the environmental quality is determined for a certain city.

$$
p(k)=\sum_{i=x}^{y} p(i) w(i)
$$

$k=1,2, \ldots \ldots, 9$

$x, y$ can be obtained respectively depending on $k$

where:

$p(k)$ : the quality synthesis index of environmental element $k$

$p(i)$ : the quality index of environmental criteria $i$

$w(i)$ : the quality weight of environmental criteria i

P, the synthesis index of city environment, can be obtained as follows:

$$
P=\sum_{k=1}^{9} w(k) p(k)
$$

$w(k)$ : the quality weight of environmental element $k$

The class of the city ecological environmental quality can be determined after the comparison of $P$ with the established classified standard value (4 value) of city ecological environmental quality mentioned above has been made.

The above mentioned method has been used in our research to determine the environmental quality class of 20 Chinese big cities in 1984. The results are shown in table 2. 
Table 1 Quality Weights System of city ecological environment on the basis of AHP

\begin{tabular}{|c|c|c|c|c|c|c|c|}
\hline \multicolumn{4}{|c|}{ Quality weights of environmental elements } & \multicolumn{4}{|c|}{ Quality weights of environmental criteria } \\
\hline \multirow{2}{*}{ Items } & \multicolumn{2}{|c|}{ Weights } & \multirow{2}{*}{ C. $R$} & \multirow{2}{*}{ Items } & \multicolumn{2}{|c|}{ Weithts } & \multirow{2}{*}{ C. R } \\
\hline & Caiculated & Rounded & & & Calculated & Rounded & \\
\hline Atmosphere & 0.161792 & 0.162 & & $\begin{array}{c}\text { Sulphur dioxide } \\
\text { Nitrogen oxide } \\
\text { Total suspended } \\
\text { solids }\end{array}$ & $\begin{array}{l}0.2579 \\
0.1992 \\
0.54299\end{array}$ & $\begin{array}{l}0.26 \\
0.20 \\
0.54\end{array}$ & 0.0135 \\
\hline Waterbody & 0.174253 & 0.174 & & $\begin{array}{l}\text { Solvent oxygen } \\
\text { Oxygen for } \\
\text { Biochemistry } \\
\text { Ammonia nitrogen } \\
\text { Nitrite nitrogen } \\
\text { Volatile phenol } \\
\end{array}$ & $\left\{\begin{array}{l}0.1244 \\
0.21702 \\
0.3822 \\
0.110845 \\
0.1665 \\
\end{array}\right.$ & $\begin{array}{l}0.12 \\
0.22 \\
0.38 \\
0.11 \\
0.17 \\
\end{array}$ & 0.0065 \\
\hline Noise & 0.118188 & 0.118 & & Traffic noise & & 1.00 & \\
\hline Population & 0.16404 & 0.164 & & Density of population & & 1.00 & \\
\hline Living, material & 0.09602 & p.096 & b. 07988 & \begin{tabular}{|l|} 
Housing area \\
Number of commercial \\
$\quad$ services \\
Rate of gasification \\
Consumption of \\
service water \\
Consumption of \\
service electricity
\end{tabular} & $\begin{array}{l}0.3053 \\
0.1654 \\
0.2367 \\
0.1065 \\
\cdot \\
0.1861 \\
\end{array}$ & $\begin{array}{l}0.30 \\
0.17 \\
0.24 \\
0.11 \\
0.18\end{array}$ & 0.0277 \\
\hline Transportation & 0.094717 & 0.095 & & $\begin{array}{l}\text { Number of vehicles } \\
\text { Area of traffic roads }\end{array}$ & $\begin{array}{l}0.50 \\
0.50\end{array}$ & & \\
\hline $\begin{array}{l}\text { Medicine and } \\
\text { sanitation }\end{array}$ & 0.743529 & 0.074 & & $\begin{array}{l}\text { Number of hospitals } \\
\text { Number of } \\
\text { hospital beds } \\
\text { Number of doctors }\end{array}$ & $\begin{array}{l}0.33 \\
0.33 \\
0.34 \\
\end{array}$ & & \\
\hline Recreation & 0.03465 & 0.035 & & \begin{tabular}{|l|} 
Number of theatres \\
Number of green area
\end{tabular} & $\begin{array}{l}0.52 \\
0.48 \\
\end{array}$ & & \\
\hline $\begin{array}{l}\text { Culture and } \\
\text { education }\end{array}$ & 0.0819 .47 & 0.082 & & $\begin{array}{l}\text { Number of students } \\
\text { in middle schools } \\
\text { Number of students } \\
\text { in the universities } \\
\text { Number of scientists } \\
\text { and technicians }\end{array}$ & $\begin{array}{l}0.33 \\
0.33 \\
0.34\end{array}$ & & \\
\hline
\end{tabular}


The experience indicates that with adoption of AHP, the weights system of the city ecological environmental quality can be determined with a satisfactory result so as to provide a scientific foundation for determining the quality class of city ecological environment.

Table 2 Results of Determining Quality Class of City Ecological Environment

\begin{tabular}{lcl}
\hline Items & $\begin{array}{c}\text { Environmental quality class } \\
\text { (Grade) }\end{array}$ & Coridition of quality \\
\hline Changsha & 3 & polluted (pass) \\
Wuhan & 3 & polluted (psaa) \\
Kunming & 3 & polluted (pass) \\
Suzhou & 3 & polluted (pass) \\
Fuzhou & 3 & polluted (pass) \\
Hangzhou & 3 & polluted (pass) \\
Harbin & 3 & polluted (pass) \\
Chongqing & 4 & seriously polluted (poor) \\
Xian & 4 & seriously polluted (poor) \\
Chengdu & 4 & seriously polluted (poor) \\
Beijing & 4 & seriously polluted (poor) \\
Tianjing & 4 & seriousiy polluted (poor) \\
Shijiazhuang & 4 & seriously polluted (poor) \\
Guiyang & 4 & seriously polluted (poor) \\
Shenyang & 4 & seriously polluted (poor) \\
Hefei & 4 & seriously polluted (poor) \\
Shanghai & 4 & seriously polluted (poor) \\
Jinan & 5 & extremely polluted (very poor) \\
Nanjing & 5 & extremely polluted (very poor) \\
Changchun & 5 & extremxly polluted (very poor) \\
\hline
\end{tabular}

\section{REFERENCES}

(1). Wanghuadong (1982), “The Evaluation of Environmental Quality”, China Environmental Science Press, pp 129-160

(2). Yinglonggen (1987), “An Approach of Weighting with $\mathrm{P}_{i j}$ Component Factor Analysis”, China Environmental Science, Vol.7 No.5, pp 65-69

(3). Xiejian (1986), "Application of Principal Component Analysis to Environmental Quality Assessment" China Environmental Science, Vol.6 No. 2, pp 24-26

(4). Yangxianzhi (1986), "Evaluation and Prejugement of Shanghai Civic Ecological System", Shonghai Environmental Science, No.10, pp 19-22

(5). T.L. Saaty (1986), "Absolute and Relative Measurement with The AHP. The Most Livable Cities in The United States", Socio-Econ. Plan. Sci., Vol.20 No.6. pp 327-331 
$\mathrm{a}(2)=(0.0224,0.0112,0.0112,0.445,0.224,0.1536,0 ; 1,0.2922,0.2922,0.164,0.0924,0.0924)^{\mathrm{x}}$

$\mathrm{a}(3)=(0.0156,0.0078,0.0078,0.025,0.0128,0.0087,0.005,0.299,0.299,0.168,0.09,0.094)^{-}$

Step 2: For the 2th level and the 1th jevel. establisls their weighting supermatrix.

$$
\overrightarrow{\mathrm{W}}(2)=\left[\begin{array}{ll}
\mathrm{a}(1,1) \mathrm{W}(1,1) & 0 \\
\mathrm{a}(2,1) \mathrm{W}(2,1) & I
\end{array}\right] \text {. }
$$

here, $a(1,1)=0, a(2,1)=1, W(2,1)=(0.58,0.11,0.31)^{\tau}$

Calculating $\lim _{3 \rightarrow \infty} \vec{W}(2)^{s}$, We get $W(2,1)^{* *}=(0.58,0.11,0.31)^{T}$

Step 3: synthesizing

$W(3,1)^{* *}=W(3,2) \cdot * \cdot W(2,1)^{* *}$ $=(0.276,0.138,0.138,0.0206,0.01043 .0 .0071,0.0044,0.096,0.096,0.055,0.0304,0.0304)^{\top}$

So the total estimation formulation is expressed as :

$\mathrm{N}=0.276 \mathrm{C}(11)+0.138 \mathrm{C}(12)+0.138 \mathrm{C}(13)+0.0206 \mathrm{C}(21)+0.01043 \mathrm{C}(22)+0.0071 \mathrm{C}(23)$

$+0.0044 \mathrm{C}(24)+0.096 \mathrm{C}(31)+0.096 \dot{\mathrm{C}}(32)+0.055 \mathrm{C}(33)+0.0304 \mathrm{C}(34)+0.0304 \mathrm{C}(35)$

After getting estimation value of every criteria, through $(5-1)$, we can get the total estimation value of a university's education level.

\section{六. CONCLUSION}

In this paper, we propose a new method for setting up the limiting impact priorities of the alternative level to the goal level. The advantages of this method are:

A: It's simple, clear and keeps the level's intuitiveness of the hierarchic system.

B: It avoids the calculation of big matrix.

C: The priorities of the hierarchic system both with inner dependence and independence can

be calculated.

D: This method can a!so be extended to the hierarchic system with feedback.

The authors sincerely thank professor XuShubo for his generous guidance during the research and writing stages of this project.

\section{REFERENTCE:}

1. LiuBao and LiuLin. 1987, "The Method for Priorities of System with Feedback." Master's Thesis, Dept. of Manag. Eng. . Tianjin Univ., China

2. T.L Saaty, 1987. "How to Handle Dependence with the Analytic Hierarchy Process", Mathmatical Modelling, Vol. 9, No.3-5

3. T. L Saaty, 1986. "Dependence and Independence: from Linear Hierarchies to Nonlinear Networks" European Journal of Operational Research, Vol. 26,287-237

4. XuShubo. 1986, "The Principle of the Analytic Hierarchy Process". Tianjin University. Tianjin. China. 